\title{
Electrical Problem Identified
}

National Cancer Institute

\section{Source}

National Cancer Institute. Electrical Problem Identified. NCI Thesaurus. Code C92045.

Events associated with an electrically powered device where an electrical malfunction results in a device problem (e.g. electrical circuitry, contact or component failed) even if the problem is intermittent. 